\title{
EFFECT OF SPINOSAD AND CONSULT AND THEIR MIXTURE ON THE FIFTH NYMPHAL INSTAR OF DESERT LOCUST Schistocerca gregaria (FORSK.)
}

Said, M. S. ${ }^{(1) ;}$ Th. A . Abdel - Fattah ${ }^{(1)} ;$ H. M. Sobhy ${ }^{(2)}$ and W. Z. Azer ${ }^{(2)}$

(1) Department of Locust and Grasshoppers, Plant Protection Institute, Agricultural Research Center, Dokki, Giza, Egypt.

(2) Natural Resources Department, Institute of African Research and Studies, Cairo University, Egypt

\begin{abstract}
Laboratory studies were carried out in an attempt to disclose the effect of a bio-insecticide (Spinosad), and IGR (consult) and their mixture at different concentrations (19 ppm), (123 ppm) and (9ppm of spinosad+52 ppm of consult), respectively on one day old of the $5^{\text {th }}$ nymphal instar of the desert locust, Schistocerca gregaria (Forskal) by feeding technique.

the insect enzymes acid phosphatase and Phenoloxidase activities and total carbohydrates were affected fluctuated between increasing and decreasing after 2, 4 and 6 days of treatment with Spinosad (at $\mathrm{LC}_{50}$ value), consult(at $\mathrm{LC}_{50}$ value) and their mixture(at $\mathrm{LC}_{25}$ values). acid phosphatase activity and phenoloxidase activity were dramatically declined in all treatments comparing with untreated nymphs. Highly significant decline were recorded in them by mixture. Consult caused more increase in the total carbohydrates but Spinosad and the mixture caused decrease in the total carbohydrates comparing with untreated nymphs. Highly significant decline were recorded in carbohydrate content by Spinosad.
\end{abstract}

Keywords: Schistocerca gregaria, haemolymph, activity enzymes, Spinosad, consult

\section{INTRODUCTION}

Normally, the desert locust is at low density, that occurs in desert and scrub regions of northern Africa, the Sahel (regions including the countries of Burkina Faso, Chad, Mali , Mauritania, and Niger) and Arabian peninsula( e.g., Saudi Arabia, Yemen, Oman) and parts of Asia to western India (Steedman, 1988). Grasshoppers and locusts generally have very high reproductive rates and are able to respond to favorable climatic conditions with rapid population increase (Bateman et al., 1993). During the low density phase locust populations are low and represent no economic threat. After periods of drought, when vegetation flushes occur in major desert locust breeding areas (e.g. , Indian/Pakistan border), rapid population build up and competition for food occasionally result in a transformation from low density to high density on a regional scale (Showler, 1995a). Biological control involves the use of naturally occur ring enemies-parasites, predators, and disease agents (pathogens). It also includes methods by which the pest is biologically altered, as in the production of sterile males and the use of pheromones or juvenile hormones. Most kinds of biological control agents occur naturally. Releasing more of a pest's enemies or predators into the target area can supplement this natural control. Biological control can be a low-cost control method particularly suited to low-value crops (pastureland, 
clover, and hay crops) or in areas where some injury can be tolerated (golf course fairways or forest areas) (CRC, 1998). Recently, the quality of the environment has become a major issue. Many chemicals (pesticides) previously accepted for locust control at national and international levels would not survive rigorous environmental testing. A bio-insecticide TRACER 24SC Spinosad is a new safe product to control the desert locust, Schistocerca gregaria Forskal (Hosny, et al., 2010).

Feeding application of different concentrations of Consult on the 5th nymphal instar of the desert locust, $S$. gregaria showed mortal action on treated nymphs, failure in ecdysis to adults and prolongation in the 5th nymphal age and adults had malformed wings, color changes of body and failure of completely getting rid of the last nymphal exuvia (Bakr, et al., 2009).

Therefore the objective of the present study to evaluate the effect of spinosad and consult and their mixture on the fifth nymphal instar of $S$. gregaria.

\section{MATERIALS AND METHODS}

\section{Rearing of test insects}

Nymphal instars of the desert locust, Schistocerca gregaria Forskal (Orthoptera: Acrididae) 2 days after ecdysis were used in all experiments. The individuals were taken from the sock culture maintained for several generations at the Locust Research Section, Plant Protection Research Institute (PPRI), ARC, Dokki, Giza. The insects were reared in the laboratory according to (Robert et al., 2002)

\section{Pesticides}

2.1. Spinosad

Common Name: spinosad 22.5\% SC (Suspension Concentrate)

Trade Names: Tracer ${ }^{\circledR}$

\subsection{Chitin-synthesis inhibitor}

Common name: Hexaflumuron 10\% EC (Emulsifiable Concentrate)

Trade name: Consult ${ }^{\circledR}$

3.Characterization of the haemolymph of the $5^{\text {th }}$ nymphal instar after treatment with Spinosad and consult

\subsection{Samples collection and preparation}

Fifth instar nymphs were taken for experiments under laboratory conditions. Fifty treated nymphs were divided into five replications. Nymphs were kept in cages $(25 \times 25 \times 60 \mathrm{~cm})$ at $30 \pm 2{ }^{\circ} \mathrm{C}$ and $30-50 \% \mathrm{RH}$. with a fluorescent lamp as a light source. The control insects were placed in other cages under the same conditions in $16 \mathrm{~h}$ light and $8 \mathrm{~h}$ dark (Robert et al., 2002). Samples of the haemolymph were taken at different intervals of 2, 4 , and 6 days after treatment. The haemolymph was collected through a fine puncture in the hind leg membrane and transferred into clean dry centrifuge tubes. Few crystals of phenylthiourea were added to prevent melanization before analysis. A known volume of the collected haemolymph was centrifuged on $13000 \mathrm{rpm}$ to $15 \mathrm{~min}$. to remove blood cells and pigments. Then the supernatant collected for analyses (El Gawhary, 1997). 
3.2.Determination of total carbohydrates by the phenol sulfuric acid reaction (Dubois et al., 1956).

3.3.Determination of acid phosphates in haemolymph according to the method described by Powell and smith (1954).

3.4.Determination of phenoloxidase in haemolymph based on a method described by Ishaaya (1972).

4. Calculations and data analysis:

Statistical analysis of results was statistically analyzed by analysis of variance (ANOVA) and the means were compared by L.S.D. test at 0.05 level, using SAS program (SAS, 1988).

\section{RESULTS}

\section{Determination of total carbohydrates}

The total carbohydrates contents of $5^{\text {th }}$ nymphal instar of $S$. gregaria treatment with $19 \mathrm{ppm}, 123 \mathrm{ppm}$ and $(9 \mathrm{ppm}+50 \mathrm{ppm})$ of Spinosad, consult and their mixture was determined after 2, 4 and 6 days. The effect of spinosad, consult and their mixture on total carbohydrate content of treated $5^{\text {th }}$ nymphal instar are summarized in Figure (1). There were significant differences of total carbohydrates contents at all treatments comparing with control. Carbohydrates contents were dramatically declined in treated nymphs with Spinosad and the mixture. Highly significant decline were recorded in carbohydrate content at Spinosad. Carbohydrates contents were increased in treated nymphs with consult

2.Effect of spinosad, consult and their mixture on activity of acid phosphatase (IU $/ \mathrm{ml}$ haemolymph) in $5^{\text {th }}$ nymphal instar

Results presented in Figure (2) show the activity of acid phosphatase (AcP) of $5^{\text {th }}$ nymphal instar of $S$. gregaria treated with $19 \mathrm{ppm}$, $123 \mathrm{ppm}$ and $(9 \mathrm{ppm}+50 \mathrm{ppm})$ of Spinosad, consult and their mixture. The tested compounds significantly decreased the activity of acid phosphatase as compared to the control. The activity of acid phosphatase decreased in treated nymphs with consult, Spinosad and their mixture after 2, 4, 6 days. All treatments caused decrease in Acid phosphatase activity but, the mixture gave the highest decrease in acid phosphatase activity followed by Spinosad and consult, where these values after 6days were 6.3, 7.76 and $8.5 \mathrm{IU} / \mathrm{I}$ respectively as compared with $10.2 \mathrm{IU} / \mathrm{l}$ in the control.

3.Effect of spinosad, consult and their mixture on activity of phenoloxidase (PO) (O.D. unit $\times 10^{3} / \mathrm{min} . / \mathrm{ml}$ haemolymph) in $5^{\text {th }}$ nymphal instar:

Data represented in Figure (3) showed that Spinosad, consult and their mixture caused decrease in PO activity at all treatments. The enzyme activity cleared sharply decline at all treatments. The mixture gave the highest decrease in PO activity followed by Spinosad and consult, There was a significant difference in $\mathrm{PO}$ activities by nymphs treatment at concentrations 19ppm, 123ppm and (9ppm+50ppm) of Spinosad, consult and their mixture, respectively. Two day after application there were significant differences in phenoloxidase activity between treatments and control. However, there was a large significant decrease in phenoloxidase 
activity in treated insects on $6^{\text {th }}$ day after application. Treated insects with Spinosad, consult and their mixture caused continuous reduction in phenoloxidase activity by increase the time.

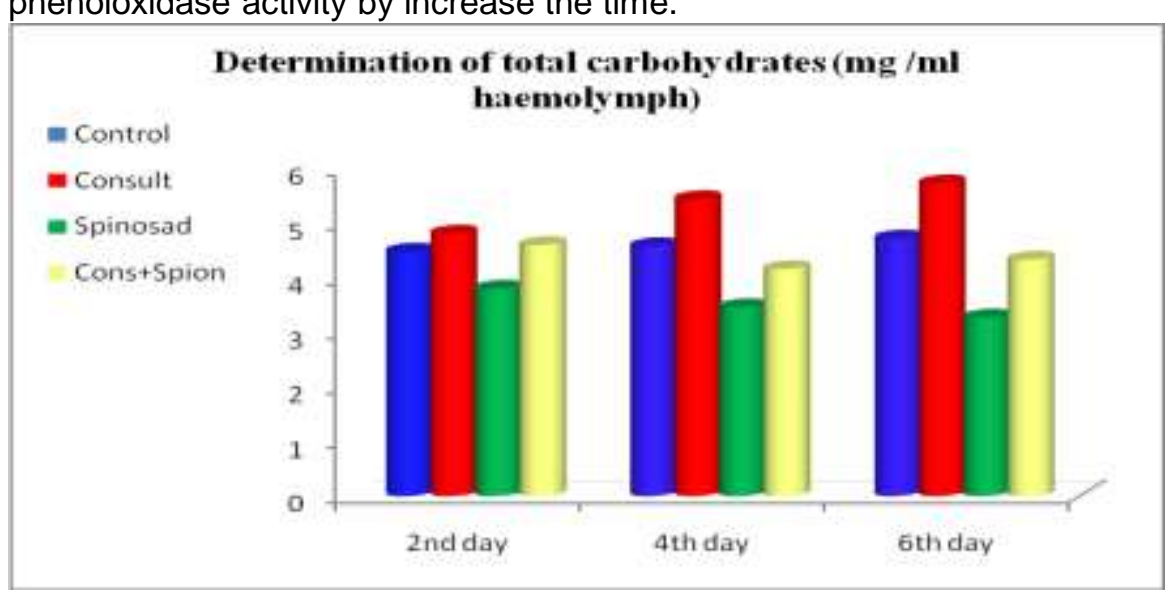

Figure(1):.Determination of total carbohydrates ( $\mathrm{mg} \% / 100 \mathrm{ml}$ haemolymph) of the $5^{\text {th }}$ nymphal instar of desert locust, $S$. gregaria after treated with spinosad, consult and their mixture.

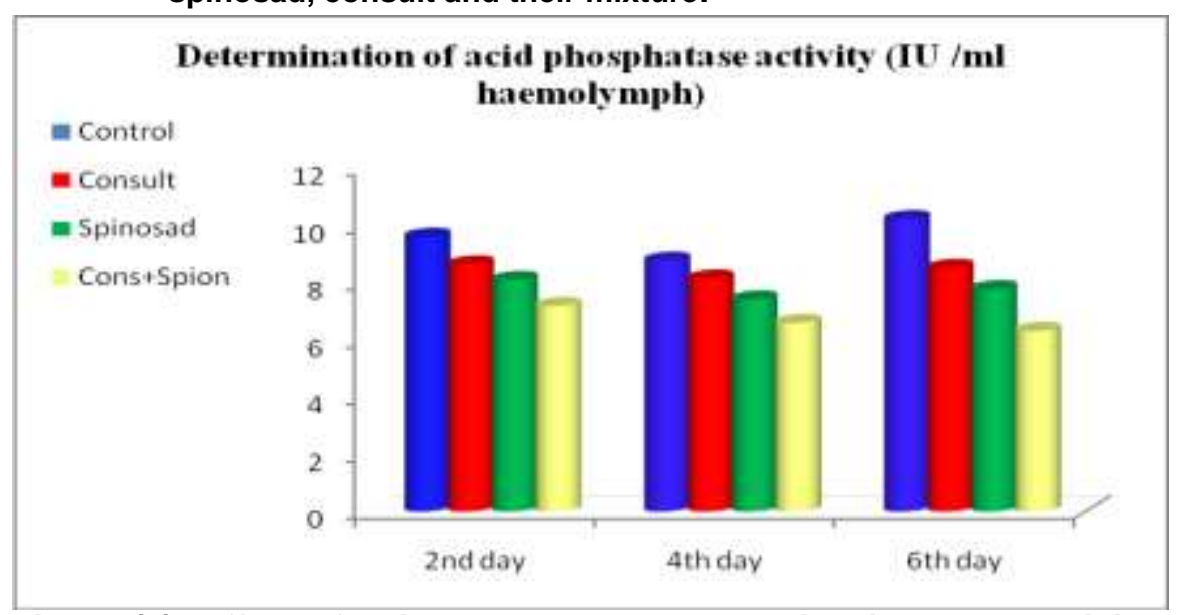

Figure (2): Effect of spinosad, consult and their mixture on activity of acid phosphatase in $5^{\text {th }}$ nymphal instar 


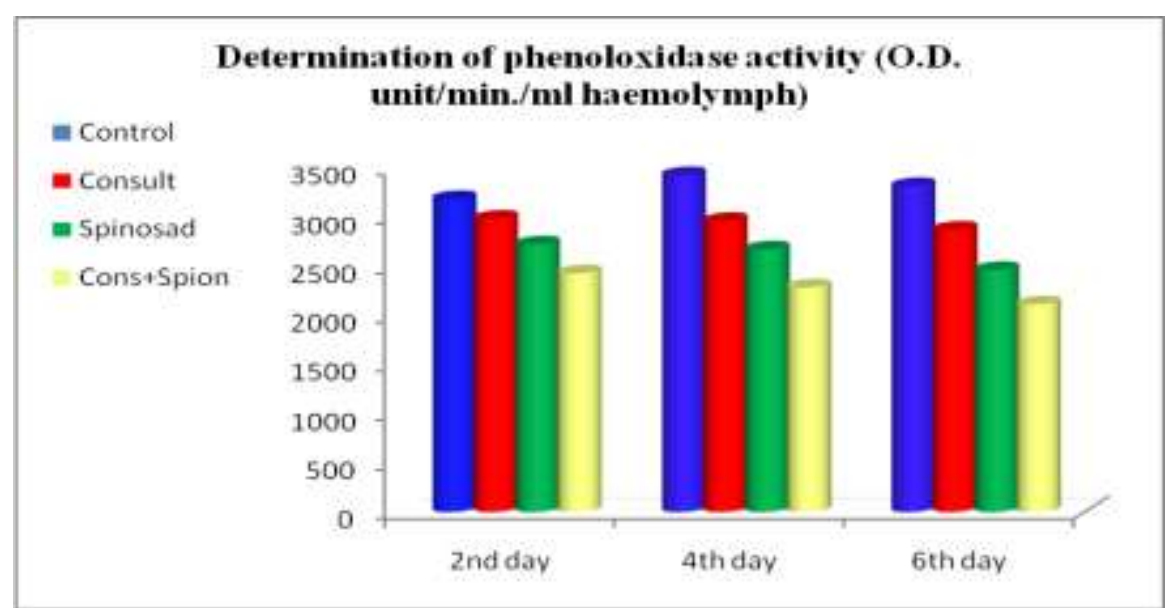

Figure (3): Effect of spinosad, consult and their mixture on activity of phenoloxidase $n 5^{\text {th }}$ nymphal instar

\section{DISCUSSION}

\section{Determination of total carbohydrates}

The two most common carbohydrate stored reserves in insects are the disaccharide trehalose and the polysaccharide glycogen. The haemolymph, fat bodies, and gut tissues are major sources of stored carbohydrates. Trehalose is usually present in large quantities in the haemolymph; and it is considered as the principal storage sugar for insects in the haemolymph. It is rapidly hydrolyzed to two glucose molecules for tissues to use. Glycogen is another form of stored energy. Insect flight muscles contain glycogen, but in small amounts which is only sufficient for a few minutes of flying. Glucose can be released from glycogen which is stored in the fatty bodies and the gut cells by hydrolysis. Some insects use carbohydrates in the haemolymph as only source of fuel to fly for 30 minutes then they switch to another source like proline or fatty acids (Nation, 2002).

In this study was found significant differences of total carbohydrates contents at all treatments comparing with control. Carbohydrates contents were dramatically declined in treated nymphs with Spinosad and the mixture during 2, 4 and 6 days after application. But, carbohydrates contents increased in treated nymphs with consult comparing with untreated nymphs. Highly significant decline were recorded in carbohydrates content at the Spinosad.

The increase in total carbohydrates content by consult in this study are in agreement with the increase in glucose (or chitin or total carbohydrates) content was noticed by El-Gammal, et al., (1993) who found increasing carbohydrate content of $S$. gregaria was triggered by chlorfluazuron. Also, Tanani et al., (2012) reported that newly molted last (5th) instar of the desert locust, S. gregaria, was treated through fresh plant food with 2 concentrations: high $(1000.0 \mathrm{ppm})$ or low $(62.5 \mathrm{ppm})$ of 3 IGR, tebufenozide. Carbohydrate content was determined in the hemolymph and 
in the fat body of the early-aged, mid-aged, and late-aged 5th instar, as well as of 1- and 4-day old adult females. Tebufenozide induced the nymphs to gain more carbohydrates. While, Hamadah, (2014) showed that all nymphs and adults had been enhanced to gain excess carbohydrates in their fat bodies. For some details, the greatest inducing effect of flufenoxuron appeared as increased fat body carbohydrates of mid-aged nymphs

On the other hand various juvenoids (JHAs), and IGRs in general, suppressed carbohydrate content in some insects, e.g., $S$. gregaria by fenoxycarb (El-Gammal et al. 1989). Newly molted last $\left(5^{\text {th }}\right)$ instar of the desert locust, $S$. gregaria, was treated through fresh plant food with two concentrations: high (1000 ppm) or low (62.5 ppm) of three IGRs: pyriproxyfen and lufenuron. Carbohydrate content was determined in the hemolymph and in the fat body of the early-aged, mid-aged, and late-aged 5th instar, as well as of one and four day old adult females. Pyriproxyfen prevented the nymphs to gain normal carbohydrate content in the haemolymph. Also, Lufenuron caused hemolymph carbohydrate content to decrease slightly in the early-aged nymphs (Tanani et al., 2012).

Reduction in carbohydrates content of treated nymphs with Spinosad in our results are in line with El-Leithy, et al, (2004) who found that total carbohydrates content in $6^{\text {th }}$ larval instar of Spodoptera littoralis (Boisd.) treated with Spinosad, $B$. thuringiensis and cypermethrin significantly decreased.

The general disturbance in carbohydrate metabolism by IGR as expressed by reduction of carbohydrate hydrolyzing enzymes activities could be result from a chain effect originating primarily from inhibition of chitin synthesis (Salem et al., 1995). The disturbance of trehalase activity might hamper the supply of glucose needed for chitin build up (Kandy and Killy, 1962).

Decreasing content of carbohydrates after treatment with spinosad may be due to a decrease in the trehalase activity or to their effects on the carboxylase activity (El-Shiekh, 2002).

\section{Effect of Spinosad, consult and their mixture on activity of acid phosphatase in $5^{\text {th }}$ nymphal instar}

Detoxification enzymes in insects are generally demonstrated as the enzymatic defense against foreign compounds and play a significant roles in maintaining their normal physiological functions (Li and Liu, 2007). Also acid phosphatase (ACP) plays an important role in the detoxification process of toxic compounds entering the body (Zheng, et al., 2007). The suppression of detoxification enzymes indicated that these enzymes play no role in the detoxification of tested compounds and may be increase the susceptibility of insect pest to these insecticides (Abd-Elaziz and El-Sayed, 2009). our study showed that the tested compounds significantly decreased the activity of acid phosphatase as compared to the control. The activity of acid phosphatase decreased in treated nymphs with consult, Spinosad and their mixture after 2, 4,6 days.

These results are not in agreement with Gillespie et al., (2000) and said (2009) who found that Acp Activity in the haemolymph of treated-desert locust, $S$. gregaria ( $5^{\text {th }}$ instar nymphs) with the entomopathogenic fungus, $M$. 
anisopliae var. acridium ( $5 \times 10^{6}$ spores $\left./ \mathrm{ml}\right)$ increased than the untreated ones.

But, these results are in agreement with some authors who applicated IGR on other insects such as Bakr, et al., (2010b) who studied the effect of the sub-lethal doses $\mathrm{LC}_{25}, \mathrm{LC}_{50}$ and $\mathrm{LC}_{90}$ of flufenoxuron (Cascade) on the activity of detoxification enzymes, acid phosphatase and the nonspecific esterases ( $\alpha, \beta$ esterases), of $2^{\text {nd }}$ and $4^{\text {th }}$ larval instars of $S$. littoralis. results showed that the activity of all enzymes decreased significantly in treated larvae at different times intervals post treatments. Also Bakr, et al., (2013) showed that tebufenozide and lufenuron exhibited a severe reduction in the activities of the detoxification enzymes, acid phosphatase and esterases (aand $\beta$ ), as compared to the control. The enzymatic activities were inhibited with the increase in the time post-treatment and also with the increase in dose. Therefore, the tested IGRs, tebufenozide and lufenuron , may be not detoxify by these enzymes.

On the other hand El-Sheikh, et al., (2009) reported that the activity of haemolymph acid and alkaline phosphatase activity was significantly increased after treatment of $S$. littoralis with Spinosad and tebufenozide.

Acid phosphatases have been shown to be associated with insect development, especially in relation to nutrition and egg maturation (Tsumuki and Kanehisa, 1984).

Ecdysone is responsible for increase in the number of lysosomes and of the activity of acid phosphatase (Radford and Misch, 1971). This indicates that the decreased activity of acid phosphatase in this study may be due to decreased number of lysosomes.

\section{Effect of Spinosad, consult and their mixture on activity of phenoloxidase (PO) in $5^{\text {th }}$ nymphal instar}

Phenoloxidase is important component of insect immuno system. In addition, phenoloxidase correlate with resistance to some parasites and pathogens across species (Nigm et al. 1997)

Our results reveal that Spinosad, consult and their mixture caused decrease in PO activity at all treatments. The enzyme activity showed sharply decline at all treatments. The mixture gave the highest decrease in PO activity followed by Spinosad and consult,

These results are in agreement with Assar et al., (2012) who showed that the activity of phenoloxidase of $4^{\text {th }}$ instar larvae of Culex pipiens ( $F$.) treated as $2^{\text {nd }}$ instar larvae with 0.1 and $1 \mathrm{ppm}$ of cyromazine. The tested IGR significantly decreased the activity of phenoloxidase.

On the other hand said (2009) reported that (Po) Activity in the haemolymph of treated-desert locust, $S$. gregaria ( $5^{\text {th }}$ instar nymphs) with the entomopathogenic fungus, $M$. anisopliae var. acridium ( $\left.5 \times 10^{6} \mathrm{spores} / \mathrm{ml}\right)$ increased than the untreated ones.

The effects of CSIs on insects vary according to species, the developmental stage at the time of application, the kind of compound and the administered dose (Mulla et al. 2003). Prevent phenoloxidase production by locust haemocytes may be as a result of destruction of the cells that produce prophenoloxidse (Cerenius et al., 1990). 


\section{REFERENCES}

Abd El-Aziz, M. F. and El-Sayed, Y. A. (2009). Toxicity and biochemical efficacy of six essential oils against Tribolium confusum (du val) (Coleoptera: Tenebrionidae). Egypt. Acad. J. biolog. Sci., 2 (2): 1 - 11.

Assar, A. A.; Abo-El-Mahasen, M. M.; Harba, N. M and Rady, A. A. (2012). Biochemical Effects of Cyromazine on Culex Pipiens Larvae (Diptera: Culicidae). Journal of American Science, 8(5):443-450.

Bakr, R. F.; Abd Elaziz, Mona. F.; El-barky, N. M.; Awad M. H. and Abd ElHalim H. M. (2013). The Activity of Some Detoxification Enzymes in Spodoptera Littoralis (Boisd.) Larvae (Lepidoptera - Noctuidae) Treated With Two Different Insect GrowthRegulators. Egypt. Acad. J. Biolog. Sci., 5(2): 19-27

Bakr, R. F.; El-barky, N.M.; Abd Elaziz, M.F. and. Abd El-Halim, H.M (2010b). Effect of Chitin synthesis inhibitors (flufenoxuron) on some biological and biochemical aspects of the cotton leaf worm Spodoptera littoralis Bosid (Lepidoptera: Noctuidae). Egypt. Acad. J. biolog. Sci., 2 (2): 43- 56.

Bakr, R. F.; Mohammed, M. I.; El-Gammal, A. M. and Mahdy, N. M. (2009). Biological effects of Chitin-synthesis inhibitor, Hexaflumuron compound on the desert locust, Schistocerca gregaria (Forskal). Egyptian Academy Journal of biological Science, 1 (1): $49-57$.

Bateman, R.; Carey, M.; Moore, D. and Prior, C. (1993). The enhanced infectivity of Metarhizium anisopliae var. acridum oil Formulations to desert locusts at low humidities. Annals of Applied Biology, 122: 145152.

Cerenius, L.; Thornqvist, P. O.; Vey, A.; Johannson, M. W. and Soderhall, K. (1990). The effect of the fungal toxin destruxin $E$ on isolated crayfish haemocytes. Journal of Insect Physiology, 36: 785-789.

CRC HAND BOOK OF PESTICIDES (1998). editor G.W.A.Milne CRC Press.

Dubios, M.; Gilles, K. A.; Hamilton, J. K.; Rebers, P. A. and Smith, F. (1956). Colorimetric method for determination of sugars and related substances. Analytical Chemistry, 28(2): 350-356.

El-Gammal, A. M.; Osman, M. A.; Shaban, O. A. and Badawy, N. S. (1993). The role of the antichitin synthesis, chlorofluazuron (IKI) on the main Metabolites during metamorphosis of Schistocerca gregaria (Forsk.). Egyptian Journal of Agricultural Research, 71:891-899.

El-Gammal, A.M.; Zohny, M.S.; Taha, G.Z.; Abdel-Hamid, M. (1989). The metabolic effect of the insect growth regulator, fenoxycarb, on Schistocerca gregaria last nymphal instar. Agricultural Research Review of Egypt, 67 (1): 125-132.

El-Gawhary, H. M. A. (1997). Biochemical Effect of Some Insect Growth Regulators. M. Sc. Thesis, Faculty of Agriculture, Cairo University, Egypt, $160 \mathrm{pp}$.

El-Leithy, M. A.; Saleh, W. D. and Fathy, H. M. (2004). Isolation and insecticidal activity of Bacillus thuringiensis strains obtained from North Sinai, Egypt. Egyptian Society for Biological Control of Pests. 14(2): 379-386. 
El-Sheikh, T. A. (2002): Effects of application of selected insect growth regulators and plant extracts on some physiological aspects of the black cutworm, Agrotis ipsilon ( Huf). Ph. D. thesis, Fac. Sci., Ain Shams Univ.

El- Sheikh. .T.A; Aziza .E .Abdel-aal and Farag , A.M. (2009). Effect of Spinosad and Tebufenozide on some biological, biochemical and immunological parameters of cotton leafworm, Spodoptera littoralis (Boisd.) Egypt. J. Agric. Res., 87 (2):73-90.

Gillespie JP, Burnett C, Charnley AK (2000). The immune response of the desert locust Schistocerca gregaria during mycosis of the entomopathogenic fungus,Metarhizium anisopliae Var acridum. J.Physiol. 46: 429-437.

Hamadah, Kh. Sh. (2014). Metabolic activity of the chitin synthesis inhibitor, Flufenoxuron, on the desert locust Schistocerca gregaria (Orthoptera: Acrididae). Journal of Entomology and Zoology Studies, 2 (1): 87-95.

Hosny, A. K. H.; Agamy, E. A.; Taha, G. Z. and El-Husseini, M. M. (2010). Influence of the Actinomycete Natural Metabolite "Spinosad" on certain locusts and grasshoppers (Orthoptera: Acrididae) in Egypt. Egyptian Journal of Biological Pest Control, 20(2): 175-177.

Ishaaya, I. (1972). Studies of the haemolymph and cuticular phenoloxidase in Spodoptera littoralis larvae. Journal of Insect Physiology, 2: 409-419.

Kandy, D. J. and Killy, B. A. (1962). Studies on chitin synthesis in the desert locust. J. Exp. Biolo., 39: 129-140.

$\mathrm{Li}, \mathrm{X}-\mathrm{Z}$ and Liu, Y-H. (2007). Diet influences the detoxification enzyme activity of Bactrocera tau (Walker) (Diptera: Tephritidae). Acta Entomologica Sinica. 50 (10): 989-995.

Mulla, M. S.; Tawatsin, A.; Chompoosri, J.; Zaim, M. and Su, T. (2003). Laboratory and field evaluation of novaluron a new acylurea insect growth regulator against Aedes aegypti (Diptera: Culicidae). J.lec Ecol., 4:241-254.

Nation, J. L. (2002). Insect Physiology and Biochemistry. CRC Press, Boca Raton London; New York, Washington, $485 \mathrm{pp}$.

Nigm,Y.; Maudlin,I.; Welburn,S. and Ratcliffe, N.A.(1997). Detection of phenoloxidase activity in the haemolymph of testse flies, refractor and susceptible to infection with Trypanosoma bruci rhodesiense. Journal of Invertebrate Pathology, 69:279- 281.

Powell, M. E. A. and Smith, M. J. H. (1954). The determination of serum acid and alkaline phosphatase activity with 4-aminoantipyrine. Journal of Clinic Pathology, 7: 245-248.

Radford, S. and Misch, D. (1971). Cytological effects of ecdysterone on the midgut cells of the flesh fly, Sarcophaga bullata. J.Cell Biol.,49:702-11.

Robert, M.O.; Andrena, K.; Goettel, M. S.; Jacques, B. and Micheal, J. B. (2002). Attenuation of fungal infection in thermoregulating Locusta migratoria is accompanied by changes in haemolymph proteins. Journal of Invertebrate Pathology, 81: 19-24.

Said, S. M. (2009). Biochemical studies on the effect of metarhizium anisopliae var. acridum infection in the desert locust, schistocerca gregaria (forskal). M. Sc. Thesis, Faculty of Agriculture, Cairo University, Egypt, 120 pp. 
Salem, I. E.; El-Sheakh, A. A.; Gomaa, E. A.; Desuky, w. M. and Raslan, S. A.(1995).Esterases and carbohydrate hydrolyzing enzymes determination in S. littoralis larvae treated with some IGRs. Zagazig. J. Agric. Res. 22 (3): 901-906

SAS Institute (1988). SAS/STAT User`s Guide, Ver. 6.03. SAS Institute Inc., Cary, North Carolina.

Showler, A. T. (1995a). Desert locust Control, Public Health, and Environmental Sustainability in North Africa. West View Press, Boulder, CO. pp 217-239.

Steedman, A. (1988). Locust Handbook. Overseas Development Agency. National Resources Institute, London, UK, pp 264.

Tanani, M. A.; Ghoneim, K. S. and Hamadah ,Kh. Sh.(2012). Comparative effects of certain igrs on the carbohydrates of hemolymph and fat body of the desert locust, Schistocerca gregaria (orthoptera: acrididae). Florida Entomologist, 95(4): 928-935

Tsumuki, H.and Kanehisa, K, (1984). Phosphatases in the rice stem borer, Chilo suppersdlis Walker (Lepidoptera, Pyralidae):Some properties and changes of the activities during hibernation.Cytobiology,21:177-82.

Zheng, Y.Z.; Lan, W.S.; Qiao, C.L.; Mulchandani, A. and Chen, W. (2007). Decontamination of vegetables sprayed with organophosphate pesticides by organophosphorus hydrolase and carboxylesterase (BI). Applied Biochemistry and Biotechnology, 136(3): 233-242.

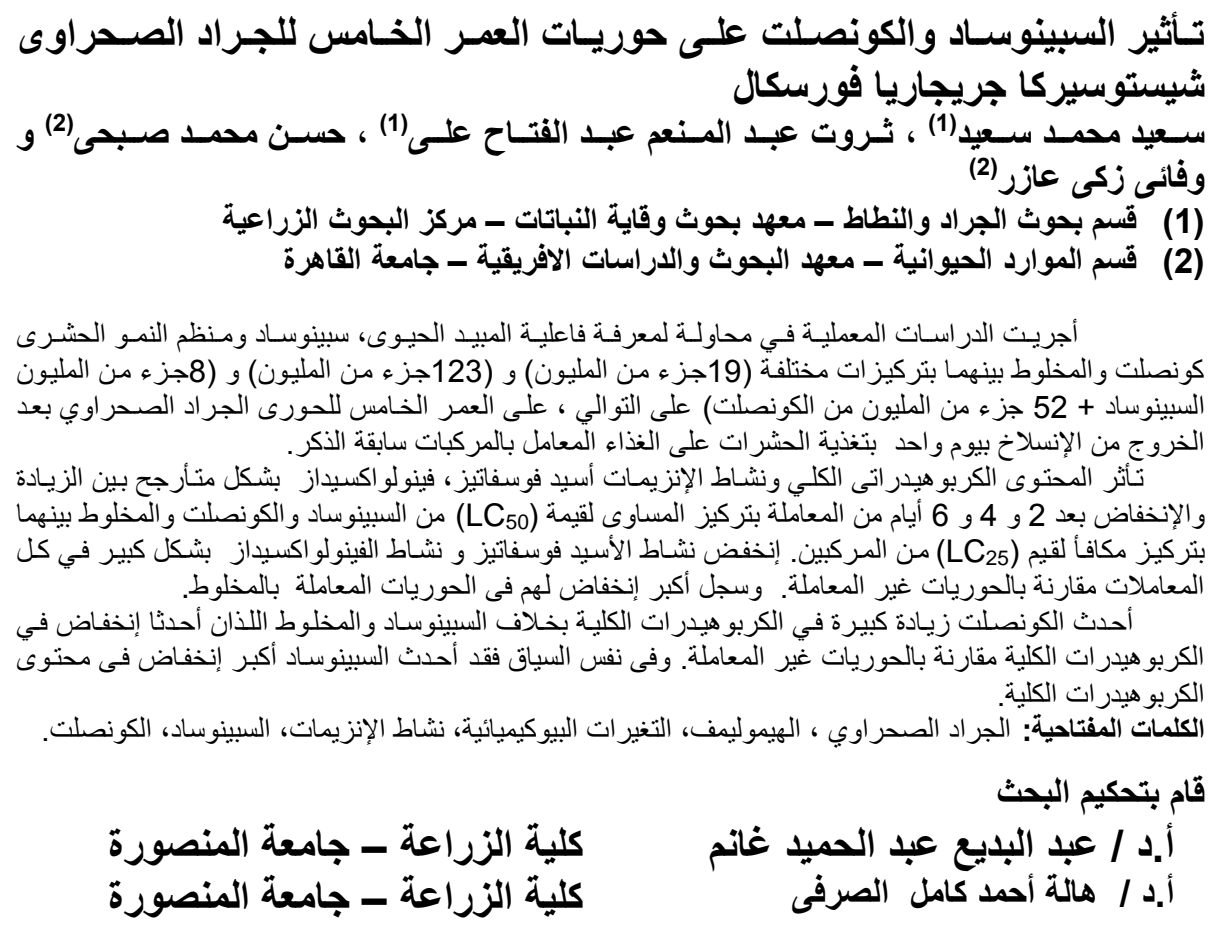

